\title{
A Study of Japanese Campus Girl Animation Characters
}

\author{
Zijia $\mathrm{Li}^{1}$ \\ ${ }^{1}$ School of Theater Film and Television, Communication University of China, Beijing, China \\ Correspondence: Zijia Li, Communication University of China, Dingfuzhuang Road, Chaoyang District, Beijing, \\ China. Tel: 86-188-1073-2167.
}

Received: April 13, 2021

Accepted: April 24, 2021

Online Published: May 6, 2021

doi:10.20849/ajsss.v6i2.892

URL: https://doi.org/10.20849/ajsss.v6i2.892

\begin{abstract}
As one of the most popular types of animation, the success of Japanese campus girl animation is closely related to the character setting that meets the aesthetic needs of the audience. The closed character of the core character is the general feature of Japanese campus girl animation works in character design. The specific expression of the closed character changes with the development of the times. This kind of works can be roughly divided into salvation of each other's relationship between classmates, friendship between teachers and students, and family relations to be remedied. It reflects the ideal psychological needs of girls in seeking pure friendship, yearning for good love, pursuing women's rights, longing for equality between teachers and students, and hoping for family love. There are also some shortcomings in Japanese campus girl animation works, such as paying too much attention to the hero's emotional development, ignoring the pressure of their entrance to school or employment, and so on. It is necessary to further analyze and summarize the rules, so as to learn from and innovate in the creation of Chinese girl animation works.
\end{abstract}

Keywords: Japanese campus girl animation, closed character, vitality guidance, mutual redemption

The story of the Japanese campus girl animation is based on the real campus life. Its events, scenes and character relationships are relatively fixed. It does not have the super powers of the strange characters of the magical girl animation, nor the bizarre world view of the mecha anime. But it still attracts generations of audiences. The unique charm of Japanese campus girl animation lies in its precise character settings, which can give the audience a full sense of substitution, so that the audience can involuntarily follow the characters to experience their campus life during the watching process. Campus girl animation has a very broad market in China, but the domestic industry cannot keep up with the audience's needs. Instead, Japanese campus girl animation dominates this market.

Therefore, this article puts the entry point on the character setting. Through studying core characters and their relationships configuration of Japanese campus girl animation, we find out the universal creation rules of excellent girl animation, so as to play a certain role in promoting the creation of animation works of similar themes of China.

\section{The Construction of Core Characters}

The target audience of campus girl animation is mainly girls between 12 and 18 years old. These audiences are experiencing or are about to experience the troubles of adolescence. In order to make they feel more empathetic to the characters, the protagonists in the animation are mostly girls between the ages of 12 and 18 . These protagonists, like most people in this audience group, are troubled by many aspects such as friendship, love, going to school, and family conflicts.

Based on these circumstances, the common characteristics of heroines in Japanese girl animation are as follows: First, appearance. Physical features that meet the needs of the average female viewer -- looks that are acceptable, but definitely not the kind of beauty that would make Prince Charming fall in love in a crowd. Second, virtue. In line with the ordinary female audience views of the character characteristics - kindness, positive, love fantasy, looking forward to love, cherish friendship and so on. As the object of young girls' love fantasy, the characters of male protagonists in Japanese campus girl animation must have the appearance characteristics to meet the aesthetic needs of young girls and the actual ability to meet the standards of young girls' mate choice. High appearance level, good grades, good sports and a sense of responsibility are the common characteristics of male protagonists in youth campus animations. In addition, the main characters mostly have the "cute attributes" 
common in Japanese anime, but these are common patterns that apply to many other types of anime.

Different from other film and television dramas, the core characters in Japanese campus girl animations have a very important characteristic, that is, "closed character". Although the character setting of this kind of character is also presented in other types of animation works, in campus girl animation, "closed character" is indispensable. The specific performance of the "closed character" even determines whether the audience can be more effectively substituted into the role, and it also determines whether the work can be widely welcomed by the animation audience. If this type of closed character is divided, it can be roughly divided into two types: "active closure" and "passive closure". "Active closure" refers to the individual keeping a distance from the outside world for active purposes. For example, in My Little Monster, the heroine Mizutani Shizuku wants to focus on learning and does not interact with classmates; "Passive closure" means being isolated by a special environment or other people when she can't choose. For example, the heroine Kuronuma Sawako in From Me to You, she has to be alone because she is isolated by her classmates.

Statistical table of the characteristics of the closed character of Japanese campus girls animated protagonists

\begin{tabular}{lcc}
\hline \multicolumn{1}{c}{ Title } & Characteristics of heroine & Characteristics of hero \\
\hline Honey and Clover (2005) & Active closure & Cheerful \\
\hline $\begin{array}{l}\text { Ouran High School Host } \\
(2006)\end{array}$ & Passive closure & Cheerful \\
\hline Our Existence (2006) & Cheerful & Active closure \\
\hline It Started with A Kiss (2006) & Cheerful & Active closure \\
\hline TIGER X DRAGON (2008) & Active closure & Cheerful \\
\hline From Me To You (2009) & Passive closure & Cheerful \\
\hline My Sister Is Lovely (2010) & Active closure & Cheerful \\
\hline
\end{tabular}

Ano Hi Mita Hana no Namae o

Bokutachi wa Mada Shiranai

Cheerful

Active closure (2011)

\begin{tabular}{lcc}
\hline Chihayafuru (2011) & Passive closure & Active closure \\
\hline My Little Monster (2012) & Active closure & Cheerful \\
\hline Say “I Love you" (2012) & Active closure & Cheerful \\
\hline My Youth Is Still Wrong (2013) & Active closure & Cheerful \\
\hline White Album2 (2013) & Active closure & Cheerful \\
\hline $\begin{array}{l}\text { Gekkan Shoujo Nozaki-kun } \\
\text { (2014) }\end{array}$ & Cheerful & Active closure \\
\hline Journey of Youth (2014) & Active closure & Cheerful \\
\hline $\begin{array}{l}\text { Wolf Girl and Black Prince } \\
(2014)\end{array}$ & Cheerful & Active closure \\
\hline Your Lie in April (2014) & Cheerful & Active closure \\
\hline 12 Years Old (2016) & Cheerful & Cheerful \\
\hline How Do You Like Me (2016) & Active closure & Cheerful \\
\hline
\end{tabular}

It can be seen from the above statistical table that in most Japanese campus girl animation works, the closed character of the heroine is mostly "active closure" (accounting for 75\%), and "passive closure" is less. And the concrete manifestation of "closed character" develops with the times.

\subsection{The "Closed Character" of the Heroine and the "Maternal Love" of the Hero}

\subsubsection{The "Closed Character" of the Female Protagonists}

The reasons and expressions of the characters' "active closure" are different. The heroine Hanamoto Kumi in 
Honey and Clover aired in 2005, grew up happily and peacefully, and has many people's favors. The expression of her closed character is only shy, introverted and not good at expressing. On the other hand, Aisaka Taiga in $T I G E R \times D R A G O N$ in 2008 witnessed the constant quarrels between her parents and the disintegration of a happy family. Her closed character is mainly reflected in the use of violence to pretend to be strong, unwilling to trust others easily, and unwilling to get close to others. In My Little Monster, which premiered in 2012, the heroine Mizutani Shizuku was influenced by the concept of her parents. She was overly obsessed with her studies and neglected her classmates and friends. As a result, her communication and communication with others have become obstacles.

In the category of passive closure, Ouran Highschool Host Club aired in the early years, the closure of the heroine Fujioka Haruhi comes from established objective factors: She is the only civilian student in the noble school and the only girl in the Ouran highschool host club. From Me to You, released in 2009, blamed the cold violence on campus for the closed character of the heroine Kuronuma Sawako.

According to the longitudinal comparison of the development of Japanese campus girl animation on the time axis, it can be seen that the heroine characteristics are set under the framework of closed character, but the causes of personality tend to be more realistic. The performance of the closed character of the characters is also more specific, and the heroine's autonomy is getting higher and higher. The frequency of the "passive closure" character is getting lower and lower. In 2014, five years after the premiere of From Me to You, the anime Shimmering Youth with a similar story setting was released. Rather than waiting passively for the rescue of a sunshine boy like Kuronuma Sawako. The heroine Yoshioka Futaba was squeezed out by classmates and suffered cold violence on campus, but she chose to use a tomboy-like shell to protect herself and actively integrate into her classmates. From this point of view, the feminist ideology of Japanese campus girl animation is gradually emerging.

\subsubsection{Gentle and Virtuous Male Protagonists}

Japanese campus girl animation usually matches the closed character heroine with a cheerful male protagonist. Compared with the male protagonists in other films and TV plays with campus themes or other types of animations, they often have the characteristics of gentle and virtuous in Japanese campus girl animation, such as being able to cook, do housework and take care of small animals.

In TIGER $\times D R A G O N$, Takasu Ryuuji is a typical gentle and virtuous male protagonist. Although he has a fierce look from his father, Takasu Ryuuji is actually quite a gentle person. He grew up in a single-parent household and his mother Maiko knew nothing about housework. Ryuuji does all the cooking and cleaning, and takes care of the family's pet parrot. While Ryuuji is more of a mother in the family, Taiko, who has to go out to work, is more like a mixture of father and daughter.

In fact, not only love as the main line of Japanese campus girl animation keen on a "gentle and virtuous" male protagonist setting, even the main emotion of the young animations also appeared such a character setting. Tachibana Makoto in Free is one such caring guy. In Japanese campus girl animation, the male protagonist is generally "gentle and virtuous", which is not only the emotional expression of the creator, but also the ideal choice of the audience. Aiming at the audience group of girl animation, the heroine in the drama often represents the audience themselves, and matches the girl's ideal boyfriend. On the contrary, the male protagonist is the hot-blooded hero image that meets the male's self-expectation. From this, we can see the great influence of cultural concept on real life and artistic ideal.

\subsection{The "Closed Character" of the Male Protagonists and the "Vigor Guidance" of the Female Protagonist}

Although in most Japanese campus girl animations, girls have closed character and boys are more cheerful, there are also opposite collocations in some works. Different from the heroine's closed character, the hero's closed character mostly comes from his parents' excessive control, or he has been severely hit by the death of his relatives and friends. The closed character of male protagonists, although not as good as the first type, can make the female audience have a strong sense of empathy for the characters' experiences, but it can reflect the female audience's desire to protect the male characters. Therefore, in this kind of works, what the audience needs to substitute into the role is not the injured hermit waiting for redemption, but the spirited girl who can save the prince from the inner demons.

In these works, the characters of the heroines seem to be almost the same, but the closed characters of the heroes change over time. Yano Motoharu, the protagonist of Our Existence (2006), is cute and handsome on the surface and popular with his classmates, but he doesn't get close to anyone. In It Started With a Kiss (2008), Irie Naoki is the prince charming in the hearts of all the girls in the school, but he has a cold personality. In these two 
animations, the male protagonists are popular with girls, but they are reluctant to make friends with others because of their own feelings. However, in the later girl animations, the cold-faced male protagonist is no longer popular with students. Ano Hi Mita Hana No Namae o Bokutachi wa Mada Shiranai (2011), Chihayafuru (2014), and Your Lie in April (2014) these three animations are a good example. This is a change from the extreme idol to the reality of campus girl animation.

Interestingly, there seems to be little difference between male and female audiences in the appeal of girl animations with closed character male protagonists.

In Japanese campus girl animation, there are also very few works that do not have the core character of closed character, but most of these works have little influence, such as 12 Years Old (2016). Its protagonists do not have a closed character, so the resistance to love is reduced, the change of growth is reduced, the plot is slightly dull.

\subsection{Analysis of the Acceptance of the Closed Protagonists}

These problems presented by animations actually come from the audience's daily life. The closed character of the protagonists generally presented by Japanese campus girl animations is not just a case of being hindered in growth, but a very common social problem. The extreme manifestation of this kind of problem development is dormancy.

Sociologists are already aware of the problem of adolescent dormancy in Japan. "Dormancy refers to a negative life state in which one deliberately avoids all social activities, including going to school, employment and family, cuts off one's contact with others, loses social behavior and closes oneself in." (Shi, Y., 2016) Although the vast majority of teenagers do not go into the extreme cul-de-sac of hibernation, the subconscious refusal to contact others, to communicate with parents and friends, and to avoid social activities is present to some extent in almost everyone.

The traditional Japanese family model is similar to that of the ancient Chinese family: grandparents and grandchildren live together and each family member is closely related to the other. However, after World War II, the traditional big family began to be broken down into small families, and the "nuclear family" composed of parents and children became one of the common characteristics of the family structure in China and Japan. In this case, as long as the parents have problems, it is difficult for the children to find a way to get rid of them in the family. They have no brothers or sisters, and most of their peers are on campus. So once they have a disagreement with their classmates and parents, there are few people they can talk to.

There are similarities in the growing environment of teenagers in China, and the problem of closed character of teenagers should not be ignored. In the research on the overall status of mental health of Chinese adolescents, the distribution of "relatively healthy" and "healthy" people is $34 \%$ and $44 \%$ respectively, indicating that more than one fifth of the Chinese adolescents' mental state is not up to the health level. (Sun, X., 2017) In addition, the rate of adolescent psychological sub-health is generally higher for girls than boys (Zhou, F., 2018), which explains why campus girl animations with closed heroine characters are more than those with closed male characters.

Animation writers have integrated the closed character of teenagers into their characters, which not only makes the audience feel more connected to them, but also provides some ways to solve the troubles of adolescence for the same age audience from the perspective of the heroine in the animations. Even audiences without mental health problems can find emotional resonance in the process of opening the hearts of the closed protagonists and attracting boys and girls. This is also an important reason why Japanese campus girl animation is so popular in China.

\section{The Construction of the Relationship Between the Main Characters}

There are almost no absolute villains in Japanese campus girl animation. Even if there is a girl who likes the male protagonist, it will certainly not have a real impact on the relationship between the male and the female protagonist. Because on campus, the biggest enemy of everyone is the troubles of adolescence, which come from love, friendship, school, family and other aspects, so the drama conflicts will unfold in the little things of campus life.

\subsection{A Mutually Redemptive Classmate Relationship}

Classmate relationship in Japanese campus girl animation has a different emphasis from that in other types of film and drama. The character setting of the girl animation is more pure in pursuit of love, and the main characters mostly present a relationship of mutual redemption. Animations are relatively short, so the growing pains are mainly focused on the obstacles to the development of the relationship between the male and female 
protagonists, which is also the biggest attraction of Japanese campus girl animation.

In this kind of works, the obstacles to love come more from the characters of both parties, more accurately from the closed character of the protagonist. Because of the closed character and unwilling or unable to communicate with people, so they can only test each other, gradually close in the test. The process of getting along with the male and female protagonists is actually a process of mutual redemption. In this process, the closed one gradually opens his heart, accepts the displeasure in his family and campus, and tolerates the outside world. The other one will also put down the paranoia he or she once had, and complete the arc of character growth. Compared with the ideal romantic relationship, the ordinary schoolmate relationship in Japanese campus girl animation is more real, with pure friendship but no permanent favoritism, and there are displeasing rivals or rivals but no dogfight. In every conflict and collision between the main characters, both sides can get a certain growth, especially the heroine who shows obvious "closed character ". For example, both Sinari and Ami are Takasu Ryuuji's reinforcements on his road to rescue Aisaka Taiga in TIGER $\times D R A G O N$.

\subsection{Friendly Relationship Between Teachers and Students}

The teacher-student relationship in Japanese campus girl animation is mostly presented as an ideal "friendship-style". Teachers can be free to students, students also maintain a certain degree of consciousness to listen to the teacher's teachings. A typical example is the class teacher Ninomiya in My Little Monster. She is in her thirties and waiting to be married with a full girl's heart. Although she sees the mixed feelings of envy and jealousy that come with students falling in love, she is also an assist for Mizutani and Yoshida together. This is probably the kind of teacher that all teenagers look forward to in their school life.

Teenagers in China also yearn for teachers like Ninomiya, but most of the films and TV dramas in China present a collection of typical characteristics of real teachers. Because there are very few cartoon works of campus girls with certain popularity in China, we will not discuss them here, but there are plenty of films and TV plays with campus themes. In Chinese film and television works, the image of the teacher is mostly strict, nagging, and teenagers have an obvious generation gap of middle-aged men. From them, you can always find the shadow of the head teacher in your middle school days. This is true even for online dramas that are more popular with young people.

\subsection{A Family Relationship to Be Repaired}

The campus theme determines the relationship between characters in this kind of works, which must be inseparable from classmates, teachers and parents. Although the campus is the main scene and the family is the second, the influence of the family on the characters is not weak at all. The state of each character when appearing has a deep relationship with the family of origin, and every Japanese campus girl animation hero and heroine's family of origin, there are not small problems.

If the open line of the work is the love story, then the dark line is basically the growth story of the hero and heroine to get rid of the shadow of childhood family and learn to communicate with others. For example, in TIGER $\times$ DRAGON the heroine Aisaka Taiga's parents divorced and each set up a new family. Although Taiga enjoys good material security, she also suffers from long-term damage caused by her parents' quarrel and divorce. Taiga tries to ease her relationship with her father, but is disappointed again by her father's neglect. Fortunately, thanks to Ryuuji's companionship and her friends' opening up, Taiga finally let go of her hatred of her parents and eased her inner pain.

Of course, there are exceptions. Some animations deliberately avoid the influence of family, such as From Me to You and Journey of Youth. Since the childhood shadow of the heroines in these works is caused by their classmates, there is almost no expression of their family situation in the animation. However, this is also the shortcomings of these several anime. In addition, in other works that express the family relationship, there must be a need for repair.

\section{Inspiration to the Creation of Chinese Campus Girl Animation}

In recent years, Chinese animation industry has enjoyed a good momentum of development. Since Monkey King: Hero Is Back, a number of animated films have been released with good box office and public praise. The low-budget anime Little Bean is also getting a lot of hits on video sites. However, the number of girl animation in China is very small, and the market still has great potential for development. Therefore, animation creators should absorb the successful experience of similar themes of excellent works in Japan, and combine with Chinese national conditions to innovate to make good works that are really suitable for the Chinese audience. 


\subsection{Experience: Correctly Express the Realistic Psychology and Aesthetic Interest of Young Girls}

With the development of society, heroines in Japanese campus girl animation have gradually improved their autonomy. To some extent, it is an artistic representation of the awakening of female consciousness and the rise of feminism in real life.

Girls strive for gender equality and women's rights. They are no longer the princesses lying in the crystal coffin waiting for the prince to save them, nor are they delicate girls who turn to boys for help in everything. They are soft and delicate, but tough and strong. These female characters are even more touching than many live-action movies and TV shows. The school rules in Chihayafuru state that girls must only wear uniform skirts, except for sports classes. But Ayase Chihaya, the heroine, was not limited by her dress. She wore sweatpants under her dress and climbed high to place the club's poster in front of the bulletin board. Instead of asking a boy for help, she accomplished her goal with her own efforts.

Many films and TV series branded as "feminist" are, in fact, arenas for male characters. There are very few plots that truly embody female activism and autonomy. They are no match for such s campus girl animation like Chihayafuru. Feminism in Japanese campus girl animation is very perceptual. It may not have the clear-cut ideology of some feminist works, but it can help foster the correct outlook on life, values and love for the young audience in a subtle way.

Since the target audience of girl animation is girls, we must not deviate from the realistic psychology and aesthetic interest of girls, which should be absorbed and used for reference in the creation of girl animation in China.

\subsection{Reflection: The Presentation of Young People's Career Pursuit Needs to Be Strengthened}

Japanese campus girl animation also has its own problems. Like most of its genre, Japanese girl animation focuses too much on the emotional development, and too little on positive guidance for teenagers in their studies, although it doesn't feature the much-criticized abortion scenes in some Chinese youth films.

For example, as we all know, teenagers in China and Japan are facing great pressure to enter a higher school or get employed, but most of the animations avoid discussing this issue. In My Little Monster, although the heroine is set as a good student who only cares about her study and doesn't care about the people around her, there are few descriptions about the pressure of entering a higher school. Especially after meeting the male protagonist, the good student is immersed in the emotional development, as if it is easy to achieve extremely good grades.

Although works of art can beautify life appropriately, they also serve a civilizing function. At the critical moment of the psychological growth of teenagers, if the animations they are exposed to show a casual attitude towards learning, then to a certain extent, it will certainly affect the learning mentality of these young audiences. The first love of adolescence is a sign to attract the audience, but the creators of campus girl animation should not only polish the sign, but also think about how to present the actual learning environment of teenagers through artistic means. This is also the place where Chinese animation creators should make innovations.

We do not intend to deny the creation method of Japanese campus girl animation, which is based on love and supplemented by the relationship between teachers, friends and family. But more willing to advocate a love career in all aspects of the creation of the method. Even if it is limited to the romantic commercial film creation field, it can also be extended to different sub-types, such as love-oriented, school-based, and co-development of love and study (or career). As long as they have the basis of reality and high artistic level, they are likely to arouse the resonance within the audience and achieve the double success of art and business. For example, the Chinese TV series Soldiers Sortie has no love scenes, and the Indian film 3 Idiots has few love scenes, but they have achieved commercial success. In a sense, they provide us with some reference coordinates of campus animation creation. We hope that Chinese campus girl animations can carry on the past and break a new path, and find a way to blossom and become popular in the context of globalization.

\section{The Conclusion}

Japanese campus girl animation is mostly adapted from manga or novels, and its target audience is very clear, which is tailored for girls aged 13 to 18 who are still in school. Previous studies on Japanese campus girl animation mostly focus on production techniques, while ignoring the social impact of them. Carefully analyzing the characters and their relationships in these popular animations, it is not difficult to find that popular works often have certain similarities.

First of all, the most important manifestation of this similarity is closed character. Why do teenage girls, the main audience, resonate with such a figure? As mentioned above, young people in both China and Japan are facing 
similar situations due to the changes in family structure and the surge of social competitive pressure. Teenagers are eager to gain a sense of identity from the characters and find a way to open their closed self. The closed personality in reality is becoming more and more common, and there are more and more closed characters in animations, which must be related to some extent. Second, in animation, if the heroine is closed, the hero will be gentle and considerate; If the hero is closed, the heroine will be full of life. "Closed character" achieves a dynamic balance in the relationship between characters. It's not hard to understand: teenagers are looking for someone to confide in, and their partners are willing to open up. This is inseparable from the girls' imagination of beautiful love and friendship. Last but not least, the feminist values conveyed by the animation characters also create excellent examples of independence, strength, courage and kindness for girls. Therefore, Japanese campus girl animation not only conforms to young girls' imagination of beautiful love and friendship in their youth, but also shows the process of closed characters' opening their hearts. Japanese campus girl animations are in line with girls' yearning for a better life in their youth, and at the same time, they spread positive and healthy energy. They provide a model for girls in this age group who are in the confused period of youth to deal with the common problems of growing up, such as learning and love. It has a realistic basis for caring about social problems, but also radiates idealism, so it is loved by the audience.

The problems encountered by Chinese teenagers in their growth process are similar to those of Japanese teenagers. The study of Japanese campus girl animations can provide new ideas for the character design of Chinese schoolgirl animations. For example, the causes of the character characteristics of the heroine and the hero and the campus environment in which teenagers grow up; or the biggest obstacle to success comes not from the villain but from the confusion of their own adolescence; or the current domestic family relations and the increasing divorce rate. In fact, the campus theme is only a small branch of the girl animation, through this category can feel the general Japanese girl animation success rules. For animation creators of the same type in China, while absorbing the common excellent characteristics of art works, they also integrate into the growing background of girls in China. Not blindly imitate, also do not carry out aimless innovation, is the correct way to produce excellent domestic girl animation. Not blindly imitate, also do not carry out aimless innovation, is the correct way to produce excellent girl animation.

\section{References}

Aoi, P. (2006). Miyazaki Hayao's Code, translated by Y. Song. Kunming: Yunnan Fine Arts Publishing House, p. 12.

Cheng, L. (2017). The Construction of Female Characters in Japanese Girls' Manga -- A Case Study of 'What Should I Do If I Am Too Popular'. People From All Walks of Life, (8).

Forster, E. M. (2009). Espects of the Novel. Beijing: People's Literature Publishing House, p. 8.

Liu, J. (2015). Character Language and Character Characteristics in the Japanese Animation 'Magic Girl まどか is Sun'. Science and Education Guide, (5).

Shi, Y. (2016). Japanese Adolescent Dormancy from the Perspective of Family Change. China Youth Social Sciences, (6).

Shi, Y. (2016). The Evolution of Social Transformation and Adolescent Dormancy in Japan. Japanese Studies, (1).

Sun, X. (2017). Analysis on the Status and Influencing Factors of Adolescent Mental Health in China. Liaoning University.

Yang, W. (2016). Feminist Imagination in Japanese Girls' Manga -- Centring on the Sex Transversion of Teenage Love. Japanese Language Learning and Research, (3).

Zhang, J. (1992). Contemporary Western Feminist Literary Criticism. Beijing: Peking University Press, p. 1.

\section{Copyrights}

Copyright for this article is retained by the author(s), with first publication rights granted to the journal.

This is an open-access article distributed under the terms and conditions of the Creative Commons Attribution license (http://creativecommons.org/licenses/by/4.0/). 